\title{
Carta aberta
}

Niterói, 19 de outubro de 2018.

Somos docentes de Psicologia nos Cursos de Graduação e Pós-graduação em Psicologia da Universidade Federal Fluminense/Niterói. Nos últimos quase 50 anos de existência da Psicologia na UFF, temos afirmado e sustentado a multiplicidade do saber psicológico, composto por diferentes abordagens teórico-práticas. A multiplicidade, no entanto, é sustentada e afirmada a partir de um eixo, uma coluna vertebral, que nos reúne: a aposta numa formação profissional que prima pela livre expressão de corpos, que se perfaz na luta diária em diversos enfrentamentos, seja contra o racismo, o machismo, o capacitismo, a transfobia, a homofobia ou contra toda e qualquer forma de violência e de opressão. A multiplicidade da Psicologia ergue-se no compromisso social e político com a afirmação de um mundo mais justo, menos desigual; com a afirmação, em última instância, da democracia.

No cenário político que se evidencia no Brasil, neste ano de 2018 que se finda, temos visto o aumento de falas preocupantes, tais como o elogio a torturadores, incentivo à opressão às minorias, proposição de políticas que implicam em retrocessos no plano dos direitos humanos, dos direitos trabalhistas, conquistados a tão duras penas em nosso país. Conhecemos a história e aprendemos com ela. Nas práticas de sala de aula, nos atendimentos clínicos e nos demais espaços de intervenção psicossocial nos quais atuamos, temos percebido que muitas pessoas estão sendo ameaçadas, agredidas e coagidas nos seus direitos de existir. O medo se faz presente no cotidiano dessas pessoas, por integrarem, de uma ou de diversas formas, grupos minoritários que se tornaram alvo de ataques, acionados pelas declarações violentas, recorrentes e insistentes. Cabe a nós, psicólogos e docentes, nos posicionarmos frente ao atual cenário para reafirmamos o direito à diversidade dos modos de vida. Defendemos ainda a liberdade de cátedra, tão fundamental para a produção científica e para o desenvolvimento do pensamento crítico, marca dos avanços teóricos, práticos e políticos de nosso campo de atuação. Por compromisso inequívoco da Psicologia, nos posicionamos pela afirmação da democracia. Podemos e devemos afirmar que o Brasil siga adiante nos direitos já conquistados, sem dar nenhum passo atrás. Esse documento é também um chamado: pela vida, pela democracia!

\section{Assinam o documento:}

Abrahão Oliveira Santos
Adriana Rosa Cruz Santos
Alessandra Lacaz
Ana Claudia Lima Monteiro
Ana Paula Lopes dos Santos
Bernadete de Lourdes Alexandre Mourão
Catarina Mendes Resende
Carlos Costa
Cecília Coimbra
Claudia Elizabeth Abbes Baeta Neves
Cláudia Osório da Silva
Cristina Mair Barros Rauter
Cristine Monteiro Mattar
Danichi Hausen Mizoguchi
Eduardo Henrique Passos Pereira
Elton Hiroshi Matsushima
Emílio Nolasco de Carvalho
Francisco de Assis Palharini
Francisco Leonel de Figueiredo Fernandes
Giselle Falbo Kosovski
Helder Pordeus Muniz
Izaque Miguel
Janes Santos Herdy
João Batista Rezende
Johnny Menezes Alvarez
José Novaes

\author{
Júlio Carlos Figueiredo \\ Katia Faria de Aguiar \\ Lilia Ferreira Lobo \\ Lucia Adriana Salgado Affonso Anhel \\ Luis Antônio dos Santos Baptista \\ Luiza Rodrigues de Oliveira \\ Marcelo Santana Ferreira \\ Marcia Oliveira Moraes \\ Maria Lídia Alencar \\ Maria Lívia do Nascimento \\ Marilene Affonso Romualdo Verthein \\ Mary Yale Rodrigues Neves \\ Maudeth Py Braga \\ Paula Land Curi \\ Paulo Eduardo Viana Vidal \\ Renata Alves de Paula Monteiro \\ Ricardo de Sá \\ Roberto Novaes de Sá \\ Silvana Mendes Lima \\ Sílvia Amorim \\ Sílvia Helena Tedesco \\ Stallone Abrantes \\ Teresa Cristina Carreteiro \\ Tiago Regis de Lima \\ Valmir Cândido Sbano
}

